\title{
MODELAGEM GRAVIMÉTRICA 3-D DE CORPOS GRANÍTICOS E BACIAS SEDIMENTARES COM EMBASAMENTO ESTRUTURAL DE DENSIDADE VARIÁVEL
}

\author{
David Lopes de Castro \\ Recebido em 04 novembro, 2005 / Aceito em 06 dezembro, 2005 \\ Received on November 04, 2005 / Accepted on December 06, 2005
}

\begin{abstract}
In the present work, a computational methodology is implemented for the modeling of three-dimensional gravity sources inserted in a basement of variable density, such as granitic bodies and sedimentary basins. This procedure proceeds by separating the gravity data into two components: the component due to variations in density of underlying basement and the component caused by the basins themselves, which will be modeled. Another product of this inversion procedure is the gravitational attraction of the basement without the effects of the modeled source. It represents another important advantage of this method. Each gravity source can be isolated and modeled. Gravity synthetic data had been generated to simulate interfering sources and test the proposed methodology. The gravity effect of a sedimentary basin had been added the gravity anomalies of intrusive bodies, simulating interfering sources. The comparison between 3-D models obtained by techniques that assume the homogeneous basement and the proposed methodology demonstrates the efficiency in the isolation of the interfering sources and in the determination of its internal geometry. The application of this technique in the Guitiriz Granite (Spain) and the Rio do Peixe rift basin (Paraíba State) demonstrates an important resolution increment of the geophysical models in the regions where interfering sources are present. In the Guitiriz Granite case, its magmatic conduits are better defined without the gravity interference of others igneous bodies. In the Rio do Peixe basin, internal structures can be differentiated with more accuracy, free from gravity anomalies associated to the Paraná Granite, which outcrops in the northern portion of the basin.
\end{abstract}

Keywords: 3-D gravity modeling, heterogeneous basement, interfering sources.

RESUMO. No presente trabalho, uma metodologia computacional é implementada para a modelagem de fontes gravimétricas tridimensionais, como granitos e bacias sedimentares, inseridas em um arcabouço estrutural de densidade variável. 0 procedimento proposto consiste em separar os efeitos gravitacionais da fonte alvo e do embasamento e, posteriormente, modelar de forma iterativa apenas a contribuição gravimétrica da fonte. Ao final do processo de inversão, é também gerado o mapa gravimétrico da região sem 0 efeito da fonte modelada. 0 que representa outra importante vantagem deste método, já que revela a assinatura gravimétrica de cada uma das fontes progressivamente, permitindo sua modelagem individual. Dados sintéticos foram gerados para testar a metodologia proposta. Os efeitos gravimétricos de uma bacia sedimentar foram adicionados a anomalias gravimétricas de corpos intrusivos, simulando fontes interferentes. A comparação entre modelos 3-D obtidos por técnicas que assumem o embasamento homogêneo e a metodologia proposta demonstra a eficiência no isolamento das fontes interferentes e na determinação de suas geometrias internas. A aplicação desta técnica no Granito de Guitiriz (Espanha) e na bacia rifte Rio do Peixe (Paraíba) revela um importante incremento de resolução dos modelos geofísicos nas regiões onde fontes interferentes estão presentes. No caso do Granito de Guitiriz, seus condutos magmáticos são mais bem definidos sem a interferência gravimétrica de outros corpos ígneos próximos. Na bacia Rio do Peixe, estruturas internas podem ser diferenciadas de forma mais acurada, livres das anomalias geradas pelo Granito Paraná, que aflora na porção norte da bacia.

Palavras-chave: Modelagem gravimétrica 3-D, embasamento heterogêneo, fontes interferentes.

Laboratório de Geofísica de Prospecção e Sensoriamento Remoto, Departamento de Geologia, Universidade Federal do Ceará, Campus Universitário do Pici, BI. 913, 60.455-760 Fortaleza, CE. Tel.: (85) 4008-9870 - E-mail: david@ufc.br 


\section{INTRODUÇ̃̃o}

Em termos de sua assinatura gravimétrica, intrusões graníticas e bacias sedimentares são unidades geológicas que apresentam vários aspectos comuns. Ambas são feições que apresentam geometrias essencialmente tridimensionais, com contatos geológicos bem definidos e estão encaixadas em um arcabouço estrutural pretérito, com o qual definem importantes contrastes de densidade. Ambas produzem padrões distintos de anomalias gravimétricas que refletem suas distribuições de massa em profundidade. Com base nestas variações sub-superficiais da densidade, técnicas de modelagem computacional permitem a transformação das anomalias gravimétricas, obtidas nas estações de medida em $10^{-5} \mathrm{~m} / \mathrm{s}^{2}$ ou $\mathrm{mGal}$, em profundidades dos limites espaciais das fontes, revelando assim sua arquitetura interna.

A modelagem gravimétrica é a técnica geofísica mais consagrada para a determinação das formas internas e profundidades de corpos graníticos e bacias sedimentares, principalmente na ausência de dados de sísmica de reflexão. No caso de granitos, a relevância da gravimetria é ainda maior, visto que seções sísmicas, além de não serem muito comuns para este fim, não costumam delimitar com clareza os contatos inferiores dos corpos intrusivos (Vigneresse, 1995). Contudo, a modelagem gravimétrica apresenta algumas limitações bem conhecidas, como uma baixa resolução vertical para grandes profundidades e a não unicidade das soluções (Condi et al., 1999). Variações de curto comprimento de onda decaem rapidamente a partir das fontes, tal que a resolução é limitada para feições que tenham seu comprimento na mesma ordem de grandeza da distância entre a fonte e 0 gravímetro. A limitação da solução não única é normalmente minimizada com a incorporação de informações independentes oriundas de outros métodos, que vincularam o problema geofísico.

A modelagem gravimétrica pode ser realizada em perfis (2D ou 2,5-D) ou em mapa (3-D) através de métodos interativos de tentativa e erro ou por procedimentos automáticos, usando-se técnicas de inversão de dados. Para a modelagem direta, as densidades e formas geométricas das fontes são assumidas e o valor da gravidade calculado é comparado com o dado observado. Para o problema inverso, a gravidade é especificada e as densidades ou a geometria ou ambas são incógnitas, que deverão ser determinadas automaticamente por procedimentos estatísticos.

Um problema adicional à modelagem gravimétrica é o fato do campo gravitacional ser aditivo, tornando o campo total a resultante do somatório dos efeitos gravitacionais das fontes presentes na região, desde a superfície até 0 manto superior. 0 efeito das fontes profundas, como o relevo da interface crosta-manto, pode ser satisfatoriamente atenuado através de filtros de separação regional-residual antes de se aplicar à modelagem gravimétrica. Contudo, a presença de fontes rasas, atribuindo um caráter heterogêneo ao embasamento do ponto de vista da distribuição de densidade, pode efetivamente distorcer o resultado final do processo inverso. Isto se esta contribuição ao campo gravitacional não for prevista no modelo geofísico proposto para o corpo granítico ou a bacia sedimentar. Várias técnicas de inversão, amplamente consagradas e utilizadas atualmente, não levam em conta tal aspecto, partindo da premissa, facilmente violada, que 0 embasamento representa um meio homogêneo (Cordell \& Henderson, 1968; Rao \& Babu, 1991; Barbosa et al., 1999; Camacho et al., 2002; Castro et al., 2002; entre outros).

Jachens \& Moring (1990) desenvolveram uma metodologia de modelagem gravimétrica 3-D que considera a possibilidade das rochas do embasamento terem densidades variáveis. 0 efeito gravimétrico da fonte em questão é separado da componente gravitacional do embasamento e só, então, invertido. Este processo é repetido inúmeras vezes até obter-se um modelo geofísico final aceitável segundo critérios estatísticos e geológicos. Um importante subproduto desta técnica é o mapa de anomalias gravimétricas da região sem a componente gravitacional devida à fonte modelada. 0 presente trabalho trata de descrever e implementar esta metodologia, adaptando-a em alguns aspectos específicos como a incorporação de modelos com densidades variáveis com a profundidade, entre outros. A metodologia proposta é testada em dados gravimétricos sintéticos em uma situação de embasamento heterogêneo e, posteriormente, aplicada em dados reais de um corpo granítico e uma bacia sedimentar. Nos casos reais, os resultados obtidos são comparados com modelos já publicados, cujas técnicas de modelagem não previam um embasamento de densidade variável.

\section{MODELAGEM GRAVIMÉTRICA 3-D}

A equação integral para a anomalia gravimétrica pode ser discretizada como a seguir,

$$
g=A p,
$$

onde $g$ é 0 vetor das medidas gravimétricas, $A$ é a matriz da função de Green contendo a distribuição espacial do meio e $p$ é 0 vetor das densidades. Determinar os parâmetros geométricos e físicos da fonte seria resolver o problema inverso,

$$
p=A^{*} g
$$

onde $A^{*}$ representa um operador matricial inverso adequado para a resolução do problema. As técnicas para solucionar o problema 
inverso podem ser dividas em três classes:

(a) métodos iterativos ou automáticos de tentativa e erro (Cordell \& Henderson, 1968; Rao \& Babu; 1991);

(b) métodos de otimização (Li \& Oldenburg, 1998; Barbosa et al., 1999);

(c) métodos que fazem uso da transformada de Fourier (Parker, 1973; Nagendra et al., 1994).

Menke (1984) e Blakely (1995) apresentam revisões detalhadas sobre a inversão de dados geofísicos.

0 problema inverso para o método gravimétrico é instável na presença de ruídos e não tem solução única. A incorporação de vínculos físicos e geológicos aos procedimentos computacionais permite a obtenção de soluções únicas e estáveis. Silva et al. (2001) listam cinco tipos básicos de vínculos:

(1) limites inferiores e superiores para os parâmetros do modelo;

(2) proximidade de um determinado parâmetro a um valor específico;

(3) proximidade entre pares de parâmetros estimados;

(4) concentração das fontes anômalas em torno de um elemento geométrico como um eixo;

(5) compactação da fonte.

Os tipos de vínculos podem ser combinados para reduzir mais drasticamente as soluções matematicamente possíveis a soluções mais próximas da realidade geológica local. Estes autores relacionam várias situações geológicas com as técnicas de inversão e os tipos de vínculos mais adequados. Para o caso de granitos e bacias sedimentares com embasamento heterogêneo, tais autores sugerem a combinação dos vínculos 2, 4 e 5 para o contraste de densidade constante ou 2 e 3 para a diminuição do contraste na bacia sedimentar em resposta ao aumento da compactação com a profundidade.

A metodologia proposta por Jachens \& Moring (1990), que será descrita detalhadamente no item "Embasamento Heterogêneo", não resolve o problema inverso diretamente, mas promove uma estratégia para separar as componentes do campo gravimétrico devido à fonte e ao embasamento. 0 efeito gravimétrico da fonte é então invertido pelo método iterativo desenvolvido por Bott (1960), que utiliza prismas verticais justapostos para modelar a geometria interna da fonte. Contudo, técnicas mais recentes permitem incorporar a compactação das rochas sedimentares com a profundidade a partir de equações lineares, exponenciais, parabólicas e hiperbólicas. Cowie \& Karner (1990) descrevem detalhadamente a correlação entre densidade e profundidade em função da variação da porosidade e seus efeitos sobre o campo gravitacional. A seguir será descrita a técnica apresentada por Rao \& Babu (1991), que substituirá no presente trabalho o método de Bott (1960) na inversão dos dados gravimétricos. 0 método de Rao \& Babu (1991) combina os vínculos 2, 3 e 5 para o procedimento matemático convergir para uma solução única e estável, como descrito abaixo.

\section{Método de Inversão}

0 problema inverso aplicado em modelagem gravimétrica pode ser realizado através de dois procedimentos básicos. 0 primeiro procedimento fixa a geometria do modelo, normalmente formado por conjuntos de retângulos idênticos ou blocos quadrados, admitindo variações de densidades entre os blocos (Braile et al., 1974; Last \& Kubik, 1983; Barbosa \& Silva, 1993). 0 segundo envolve a modelagem das anomalias gravimétricas por meio de um ou mais corpos com densidade constante e geometria variável (Talwani \& Ewing, 1960; Al-Chalabi, 1972). Neste sentido, um conjunto de prismas verticais justapostos pode modelar o relevo de uma interface que separe dois meios homogêneos com contraste de densidade regular (Fig. 1a). Seguindo esta abordagem, Rao \& Babu (1991) apresentaram um procedimento computacional para a modelagem geofísica de anomalias gravimétricas devidas a fontes tridimensionais com contraste de densidade lateralmente uniforme e parabolicamente decrescente com a profundidade. 0 modelo proposto pelos referidos autores considera que a diminuição no contraste de densidade $(\Delta \rho)$ em bacias sedimentares representa, do ponto de vista geológico, um aumento na compactação dos sedimentos em função da profundidade, que por sua vez pode ser aproximado pela seguinte função quadrática (Rao, 1986),

$$
\Delta \rho(z)=a_{0}+a_{1} z+a_{2} z^{2},
$$

onde $z$ representa a profundidade medida (positiva para baixo), $a_{0}$ é 0 valor do contraste de densidade na superfície e $a_{1}$ e $a_{2}$ são coeficientes da função quadrática.

As profundidades do relevo do embasamento são estimadas a partir das espessuras de prismas verticais justapostos, centrados sobre a malha regular obtida pela interpolação das observações gravimétricas (Fig. 1a). 0 valor inicial para a profundidade da base do prisma, ou seja, sua espessura, em um ponto $(i, j)$ qual- 

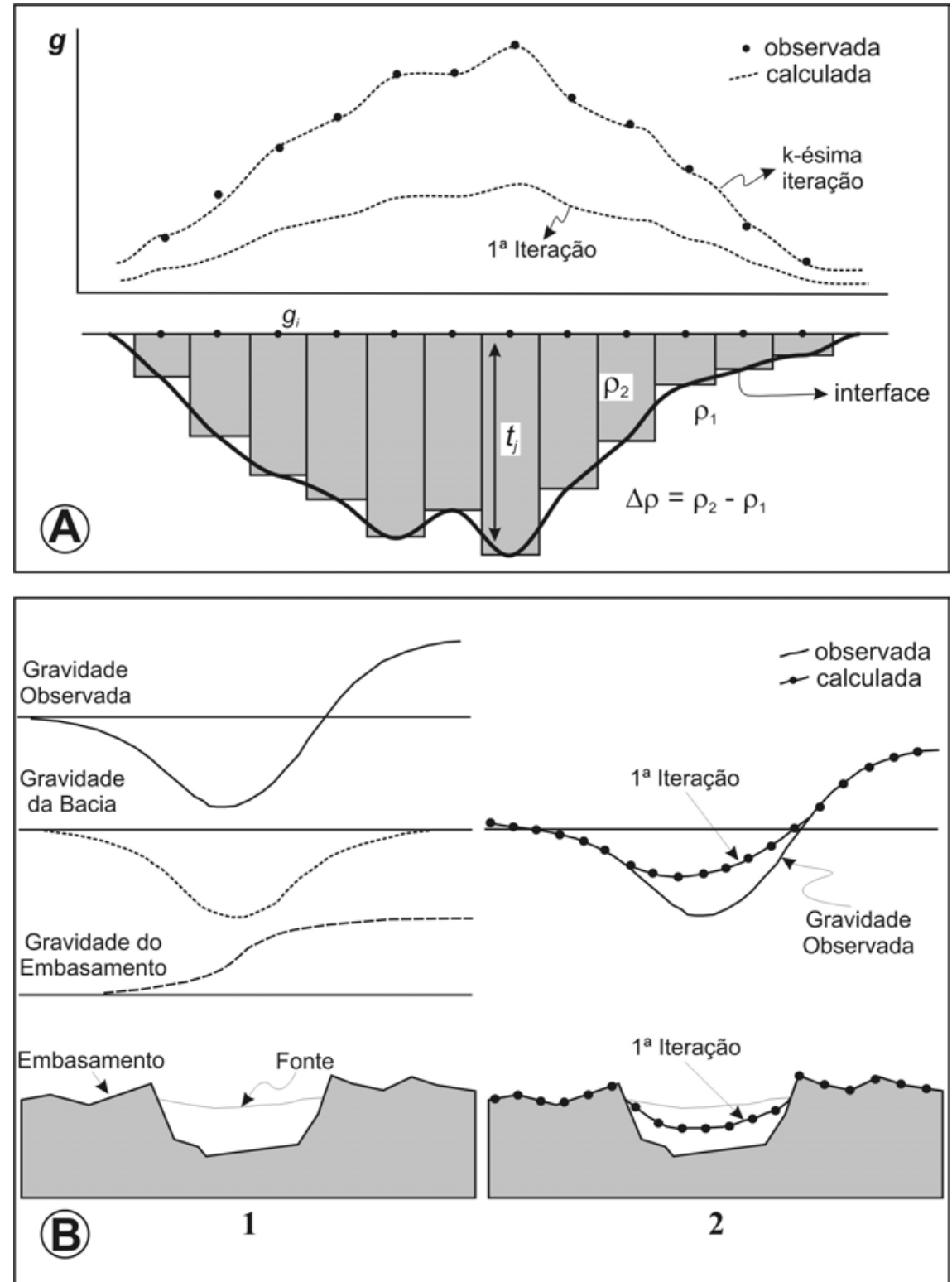

Figura 1 - Técnicas de modelagem gravimétrica considerando 0 embasamento homogêno (A) ou heterogêneo (B). A interface que separa os meios de densidades diferentes $(\Delta \rho)$ é obtida através das espessuras de prismas verticais justapostos $\left(t_{j}\right)$. Adaptado de Blakely (1995).

quer da malha é obtido por,

$$
Z(i, j)^{(1)}=\frac{g_{o b s}(i, j)}{2 \pi \gamma a_{0}},
$$

onde $g_{o b s}$ é a anomalia gravimétrica observada e $\gamma$ é a constante gravitacional universal. 0 efeito gravimétrico devido ao conjunto total de prismas $\left(g_{\text {calc }}\right.$ ) é calculado para cada ponto da malha, usando-se as espessuras obtidas nas iterações prévias. A diferença entre as anomalias observada e estimada na k-ésima iteração $\left(\Delta g^{(k)}\right)$ é calculada e então uma nova estimativa para as espessuras dos prismas é obtida pela expressão

$$
Z(i, j)^{(k+1)}=\left[\frac{\Delta g_{o b s}(i, j)^{(k+1)}}{2 \pi \gamma \Delta \rho}\right]+Z(i, j)^{(k)} .
$$

0 processo é repetido até a anomalia estimada ajustar-se satisfatoriamente à anomalia observada (Fig. 1a). 0 modelo prismático final representa a melhor estimativa para o topo do embasamento cristalino da fonte gravimétrica, fornecida pelo método 
de inversão. Nas áreas onde a anomalia gravimétrica observada tem valor contrário ao sinal do contraste de densidade, 0 algoritmo assume uma espessura igual a zero para o prisma.

A função do contraste de densidade (Eq. 3) é 0 único parâmetro a ser definido para iniciar o processo de inversão, e do qual dependem criticamente as espessuras calculadas (Blakely et al., 1999). Como pode ser observado pelas Equações 4 e 5, existe uma relação inversa entre este parâmetro e as espessuras dos prismas verticais, enquanto que a geometria interna do modelo é determinada pelo comportamento da anomalia gravimétrica. Este é um problema de ambigüidade inerente aos métodos de inversão, no qual a conjugação de valores diferentes para os parâmetros do modelo pode solucionar igualmente 0 problema geofísico. Portanto, a escolha definitiva da função contraste de densidade deve ser realizada com base em informações independentes ao método gravimétrico. Medidas de densidade de amostras de rochas aflorantes e/ou obtidas em furos de sondagens são a maneira mais direta de se definir o contraste de densidade mais adequado. Métodos de perfilagem geofísica de poços também fornecem informações detalhadas sobre a variação da densidade com a profundidade. Outro tipo de informação obtida em poços ou com base em outros métodos geofísicos, como a sísmica de reflexão, é a profundidade do topo do embasamento, que permite parametrizar o contraste de densidade da fonte.

No caso de corpos graníticos, a variação de densidade com a profundidade não é tão crítica como para bacias sedimentares, podendo-se adotar um valor constante para o contraste de densidade, determinado com base em medidas superficiais. Costa et al. (1995) não constataram nenhuma variação considerável na densidade do complexo granítico de Caçapava do Sul entre amostras superficiais e obtidas a mais de $835 \mathrm{~m}$ de profundidade em um furo de sondagem. Nas bacias sedimentares, a presença de informações sobre a densidade de subsuperfície é, via de regra, sempre mais abundante tanto por dados geofísicos quanto por dados de poços exploratórios de petróleo ou água subterrânea. Na pior das hipóteses, pode-se contar com as densidades superficiais e estimar sua variação com a profundidade, baseando-se no conhecimento da história tectono-sedimentar desta ou de outras bacias vizinhas ou correlatas.

0 vínculo da classe 2 de Silva et al. (2001) é incorporado a técnica de modelagem de maneira indireta, através das informações geológicas e/ou geofísicas independentes das profundidades do embasamento em pontos distintos. Enquanto que, os vínculos 3 e 5 são incorporados diretamente nas Equações 4 e 5 através da suavidade e compactação, neste caso ausência de espaços vazios, do modelo de prismas verticais justapostos.

\section{Embasamento Heterogêneo}

A contribuição de uma distribuição de densidade heterogênea das rochas do embasamento ao campo gravitacional será incorporada à modelagem geofísica seguindo o procedimento apresentado por Jachens \& Moring (1990) e descrito detalhadamente por Blakely (1995). Esta metodologia tenta separar as componentes do campo devidas à fonte $\left(g_{d}\right)$ e as variações de densidade no embasamento $\left(g_{b}\right)$ (Fig. 1b). A seqüência original foi adaptada neste trabalho para permitir a variação da densidade da fonte com a profundidade. As etapas do procedimento proposto são apresentadas a seguir:

a) a primeira iteração assume que $g_{b}$ é definido por apenas aquelas estações localizadas na região onde aflora $0 \mathrm{em}$ basamento, ou seja não considera as estações na área da fonte em apreço. A interpolação destes dados em uma malha regular irá gerar uma superfície gravimétrica suavizada na região da fonte (Fig. 1b). Este malha constitui a primeira aproximação para $g_{b}^{(1)}$, porém é apenas uma estimativa pobre já que as estações próximas a bacia ainda incorporam os efeitos gravimétricos da fonte;

b) a primeira aproximação para $g_{d}$ é obtida pela subtração de $g_{b}^{(1)}$ dos dados gravimétricos observados. A primeira estimativa para a geometria interna da fonte $\left(Z^{(1)}\right)$ é calculada pela inversão de $g_{d}^{(1)}$ pelo método de Rao \& Babu (1991);

c) 0 efeito gravimétrico da fonte é então calculado a partir do modelo de prismas verticais justapostos de densidade variável de Rao et al. (1990) e subtraído dos valores das estações do embasamento para produzir uma nova aproximação para a gravimetria do embasamento $g_{b}^{(2)}$.

As etapas b) e c) são repetidas até a solução convergir para uma separação das anomalias da fonte e embasamento satisfatória. Como produtos finais deste procedimento têm-se a arquitetura 3$D$ da fonte e o campo gravimétrico do embasamento sem 0 efeito desta mesma fonte.

\section{DADOS SINTÉTICOS}

Um modelo sintético foi gerado com o intuito de testar a aplicabilidade da metodologia desenvolvida por Jachens \& Moring (1990) e adaptada neste trabalho para a modelagem gravimétrica 3-D de corpos graníticos e bacias sedimentares em regiões cujo embasamento apresenta uma distribuição de densidade variável. 0 modelo geofísico é formado por uma bacia rifte localizada no limite de dois domínios crustais, intrudidos por corpos ígneos 
(Fig. 2a). A bacia é formada por um semi-graben, com dois depocentros com profundidades de até $4,05 \mathrm{~km}$, orientados segundo a direção SW-NE, e cuja falha principal de borda é representada pela reativação de uma zona de cisalhamento pretérita. 0 caráter heterogêneo do embasamento é simulado por fontes profundas, os dois domínios estruturais, e por fontes rasas, um corpo anfibolíico a oeste da bacia e uma intrusão granítica na sua borda nordeste. Estes últimos geram anomalias gravimétricas positivas e negativas, respectivamente. Na Tabela 1 estão dispostos os parâmetros do modelo geofísico. 0 contraste de densidade utilizado nas modelagens gravimétricas foi igual ao valor real do modelo sintético.

Tabela 1 - Parâmetros físicos e geométricos do modelo geofísico.

\begin{tabular}{|l|c|c|c|}
\hline & $\begin{array}{c}\text { Densidade } \\
\left(\mathrm{g} / \mathrm{cm}^{3}\right)\end{array}$ & $\begin{array}{c}\text { Profundidade } \\
\text { máxima }(\mathrm{km})\end{array}$ & $\begin{array}{c}\text { Volume total } \\
\left(\mathrm{km}^{3}\right)\end{array}$ \\
\hline Domínio crustal I & 2,80 & 40,0 & - \\
\hline Domínio crustal II & 2,78 & 40,0 & - \\
\hline Corpo anfibolítico & 2,92 & 0,89 & $1.657,35$ \\
\hline Intrusão granítica & 2,67 & 2,18 & $4.979,68$ \\
\hline Bacia sedimentar & 2,54 & 4,05 & $7.541,83$ \\
\hline
\end{tabular}

A partir do algoritmo desenvolvido por Rao \& Babu (1991), o campo gravitacional foi calculado em uma malha regular com 101 linhas e 101 colunas e espaçamento de 2,0 km. Para simular dados reais, foi adicionado um ruído pseudo-aleatório com desvio padrão de $2,5 \%$ do valor absoluto máximo das anomalias gravimétricas sintéticas (-39,85 mGal). A Figura $2 b$ mostra 0 mapa de anomalias gravimétricas final, onde se observa um suave gradiente gravimétrico de NW para SE $(0,013 \mathrm{mGal} / \mathrm{km})$, uma anomalia positiva $(2,0 \mathrm{mGal})$ no limite oeste da área e duas importantes anomalias negativas nas porções central e NE devidas à bacia sedimentar e à intrusão granítica ( $\approx-40 \mathrm{mGal})$.

Se o presente problema geofísico for considerado como a modelagem de uma interface que separa dois meios homogêneos, 0 efeito gravimétrico negativo devido ao granito será incorporado automaticamente ao modelo geofísico a ser ajustado para a bacia (Fig. 3a). Nesta região, a não homogeneidade do embasamento é uma grave violação da premissa original, o que compromete localmente os resultados finais do método de inversão.

A contribuição de outras fontes, como no caso do granito deste exemplo, é difícil de ser dimensionada e atenuada. Mesmo com 0 uso de técnicas de modelagem mais sofisticadas que conjugam diferentes tipos de vínculos (Barbosa et al., 1999; Camacho et al., 2002), a presença de fontes interferentes não previstas no modelo influenciam negativamente na precisão dos procedimentos de inversão. Nas áreas onde tal premissa apresenta-se mais próxima da realidade geológica local, a geometria interna da bacia é reconstituída de forma bastante satisfatória pela modelagem gravimétrica (Fig. 3a).

0 método de Jachens \& Moring (1990) foi aplicado aos dados gravimétricos sintéticos seguindo o procedimento descrito anteriormente. As estações na região da bacia sedimentar foram suprimidas para gerar a primeira estimativa da gravidade do embasamento. As etapas seguintes foram repetidas seis vezes, sendo que a terceira iteração apresentou os resultados mais satisfatórios (Fig. 3b). Em especial na porção NE, onde se localiza o granito, a arquitetura interna da bacia é bem reconstituída. Os contatos superficiais e os depocentros mostram-se concordantes com o modelo sintético. 0 erro médio ficou estabilizado na ordem de $100 \mathrm{~m}$, ou seja, menos de 2,5\% da profundidade máxima da bacia. Uma comparação entre o modelo original da bacia e os resultados das modelagens 3-D para o embasamento homogêneo e heterogêneo é apresentada no perfil A-A' da Figura 3.

0 segundo produto gerado pela inversão assumindo um embasamento heterogêneo é o mapa de anomalias gravimétricas sem o efeito da bacia. Ou seja, seria uma reconstituição teórica do embasamento caso não houvesse 0 evento geológico que produziu a fonte gravimétrica em questão. A Figura 4 mostra a comparação entre este mapa e 0 campo gravitacional do modelo sintético, não incluindo a gravidade devida à bacia. Na região da bacia, encontram-se apenas dados espúrios, resíduos da inversão dos dados corrompidos pela inclusão do ruído aleatório. Por fim, destaca-se neste mapa (Fig. 4a) a anomalia referente ao granito, que nos dados sintéticos estava mascarada pelo efeito da bacia (Fig. 2a), pode ser visualizada corretamente.

\section{DADOS REAIS}

A seguir serão apresentados dois casos reais de embasamento heterogêneo para testar a aplicabilidade da metodologia apresentada. 0 primeiro caso é 0 do Granito de Guitiriz na Espanha associado a uma série de corpos plutônicos, alojados em uma região de transpressão (Aranguren et al., 1995). 0 segundo caso é 0 da bacia Rio do Peixe (PB), posicionada nos limites de três domínios crustais, em uma região intensamente afetada por intrusões graníticas (Castro et al., 2006).

\section{Granito de Guitiriz}

0 granito Guitiriz intrude rochas metamórficas pré-cambrianas e ordovicianas, pertencentes ao domínio Ollo de Sapo da porção norte da província Variscan da Espanha (Aranguren et al., 1995). 0 domínio crustal é limitado por zonas de cisalhamento trans- 


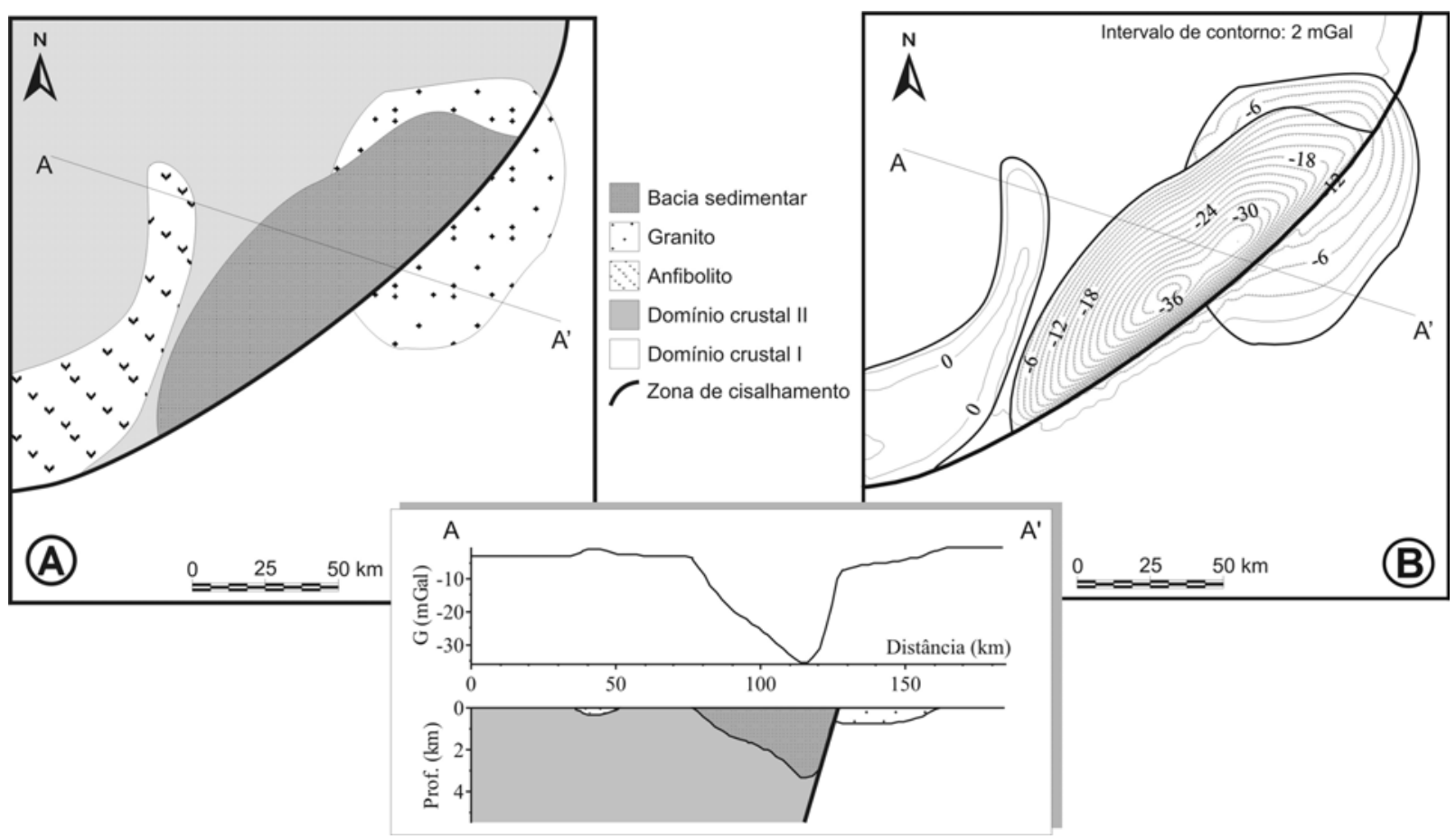

Figura 2 - Dados gravimétricos sintéticos (B) gerados a partir de um modelo geofísico de bacia sedimentar com embasamento heterogêneo (A) para testar as técnicas de inversão discutidas no texto. Os parâmetros do modelo são descritos na Tabela 1.

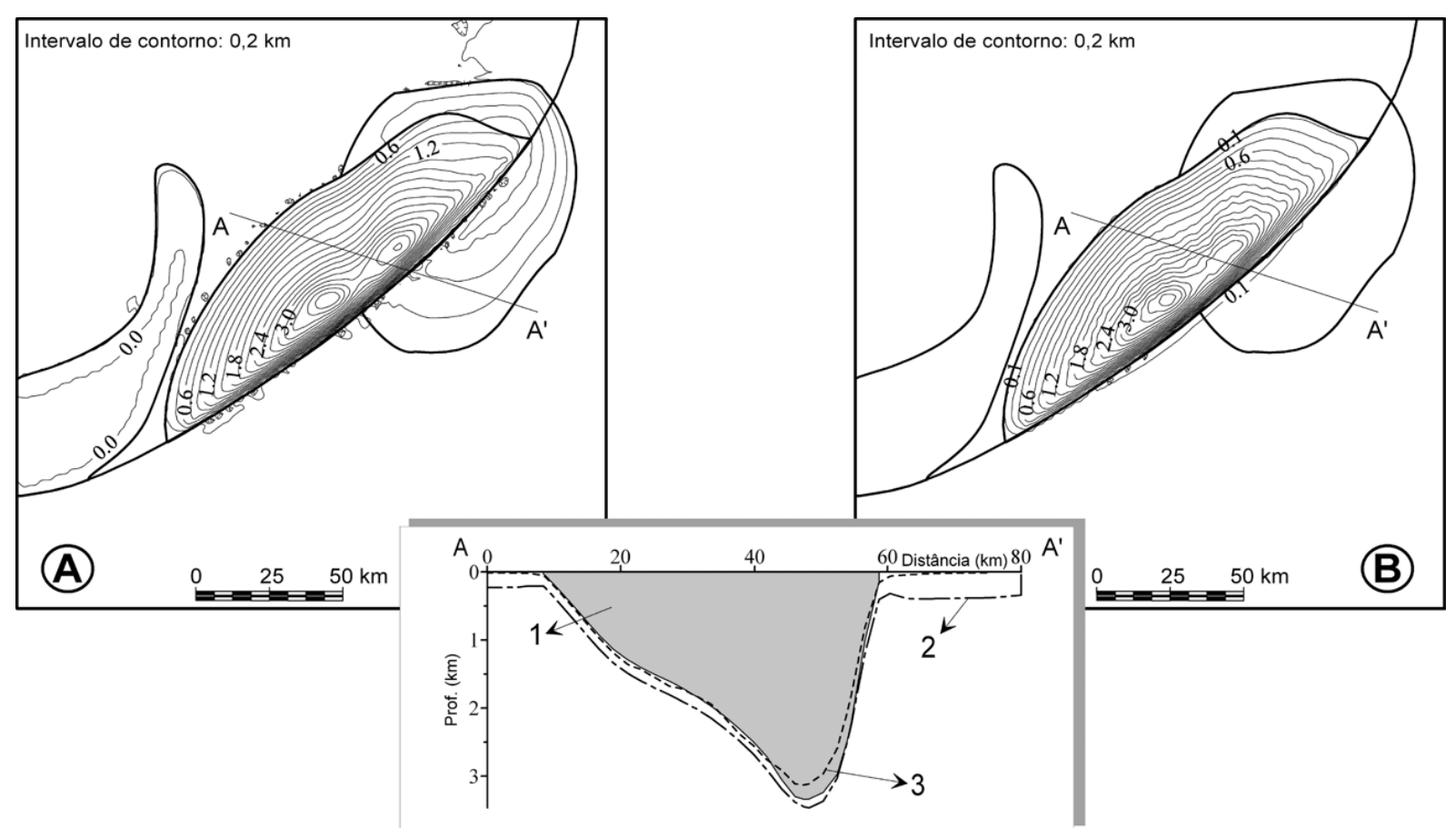

Figura 3 - Geometrias internas da bacia sedimentar obtidas através das técnicas de inversão para o embasamento homogêneo (A) e heterogêneo (B). Uma comparação entre o modelo original da bacia (1) e os resultados das modelagens 3-D (2 - homogêneo e 3 - heterogêneo) é apresentada no perfil A-A'. 

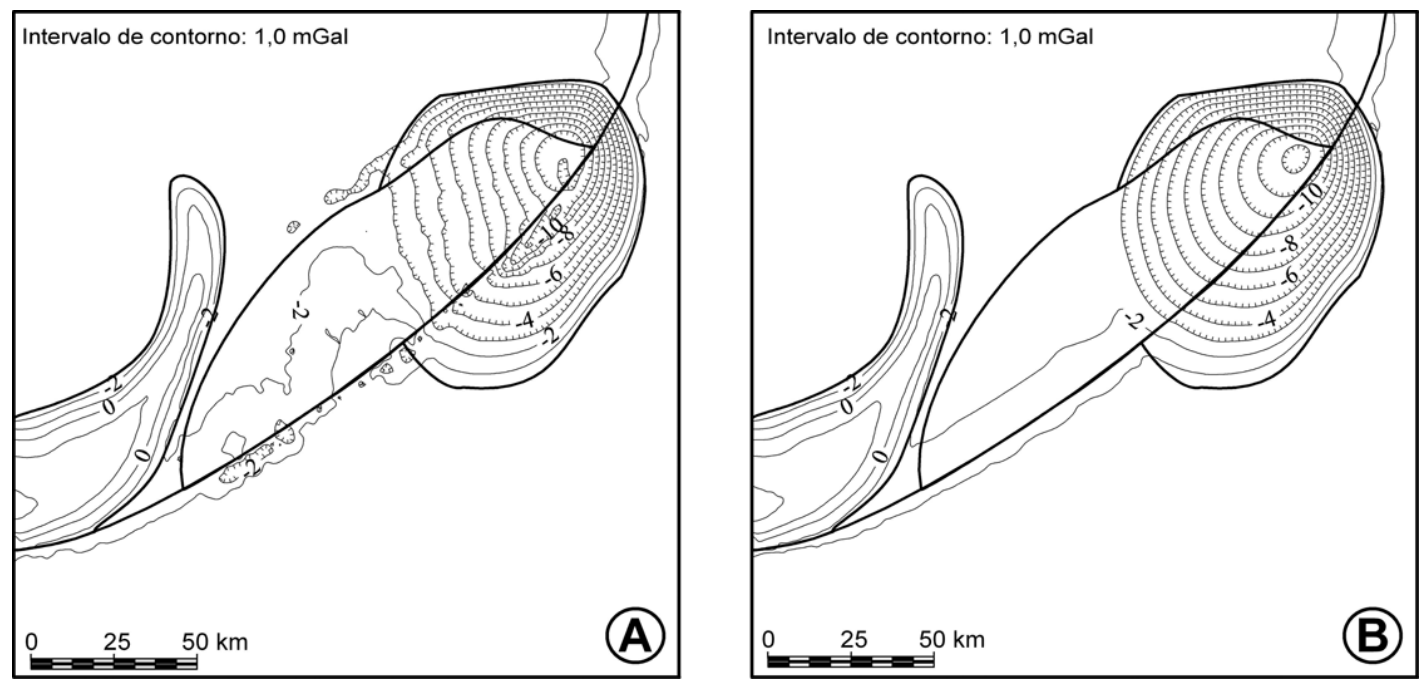

Figura 4 - Mapas de anomalias gravimétricas do modelo teórico: (A) obtido através da modelagem gravimétrica considerando 0 embasamento heterogêneo e (B) sem incluir a gravidade devida à bacia sedimentar.

correntes N-S, que produziram uma região de escape tectônico, permitindo 0 alojamento de corpos graníticos. 0 efeito gravimétrico do granito Guitiriz e de dois outros corpos intrusivos é mascarado por um suave gradiente regional de orientação NW-SE (Fig. 5a). Após realizada a separação das componentes regionais e residuais do campo gravitacional através de um ajuste polinomial robusto desenvolvido por Beltrão et al. (1991), percebe-se mínimos gravimétricos nas regiões dos granitos de até -10, 6 mGal (Fig. 5b), bem como anomalias positivas e negativas de curto comprimento de onda em torno do granito Guitiriz. Tal assinatura geofísica configura um arcabouço estrutural com importantes variações de densidade, violando em parte a premissa adotada pelo método de inversão de Cordell \& Henderson (1968), escolhido pelos autores. Ou seja, o problema geofísico em questão não trata puramente da separação de dois meios homogêneos.

A componente residual dos dados gravimétricos foi invertida pelo método de Rao \& Babu (1991) para o embasamento homogêneo e pelo procedimento descrito neste trabalho e, posteriormente, comparada com o modelo geofísico obtido por Aranguren et al. (1995) (Fig. 6). No geral, as geometrias de subsuperfície obtidas pelas três técnicas são bastante semelhantes, revelando um corpo ígneo essencialmente tabular com zonas mais espessas de até $5,0 \mathrm{~km}$, concentradas nas porções oeste e norte do granito. Estas áreas são interpretadas como os principais condutos do magma granítico. Variações de menor magnitude entre os modelos que consideram o embasamento homogêneo (Figs. 6a e 6b) são devidas a diferenças conceituais e metodológicas no desenvolvimento dos diferentes métodos de separação da componente residual e de inversão utilizados.

Na porção sul do granito Guitiriz, concentrações sutis de massa granítica representam a influência de anomalias negativas próximas aos limites oeste e leste do corpo. 0 mesmo ocorrendo na sua borda norte. Enquanto que no limite nordeste, a deficiência de massa é provavelmente causada por uma anomalia positiva de 6,5 mGal, também próxima ao granito (Fig. 5b). Tais observações só são possíveis pela comparação com o modelo gerado pelo método de inversão que considera 0 embasamento heterogêneo (Fig. 6c). Este resultado foi obtido após a terceira iteração e mostra um melhor ajuste entre os contatos superficiais do granito e a isolinha de $0,0 \mathrm{~m}$ de profundidade do modelo. As raízes do corpo estão aparentemente mais bem definidas, principalmente suas porções leste e sudeste.

\section{Bacia Rifte Rio do Peixe}

No extremo oeste do estado da Paraíba, encontra-se a bacia rifte Rio do Peixe, com uma área de cerca de $1.000 \mathrm{~km}^{2}$. Esta faz parte uma série de bacias sedimentares de pequeno a médio porte, formadas pelos esforços tectônicos que culminaram com a abertura do Atlântico Sul, no Cretáceo Inferior (Matos, 1992). Seu arcabouço estrutural é composto por três domínios crustais distintos, intensamente deformados por extensas zonas de cisalhamento e intrudidos por corpos graníticos. A bacia sedimentar é dividida em três sub-bacias, separadas por altos estruturais (Fig. 7a). Cada sub-bacia é formada por semi-grabens, cujas fa- 

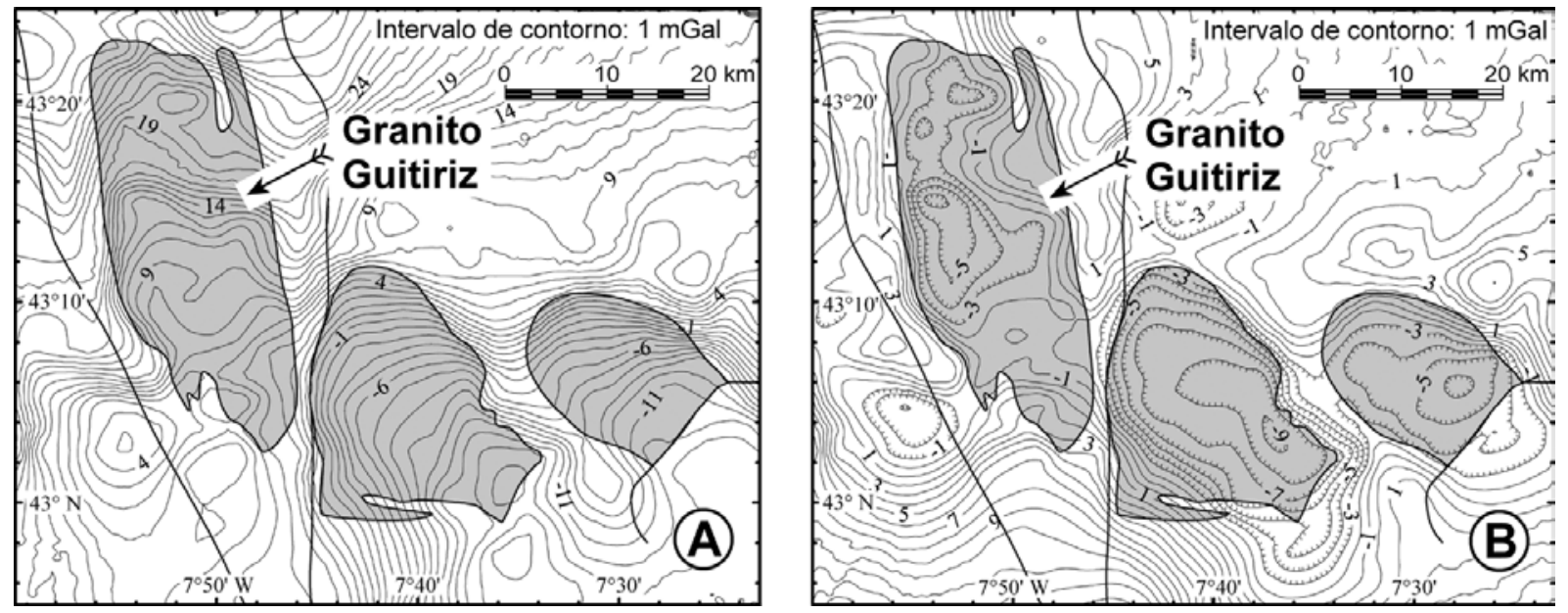

Figura 5 - Mapa de anomalias gravimétricas do granito Guitiriz (A), digitalizado de Aranguren et al. (1995) e a componente residual do campo gravitacional obtido através do ajuste de uma superfície polinomial de ordem 1 (B). As áreas preenchidas representam corpos graníticos e os traços zonas de cisalhamento.
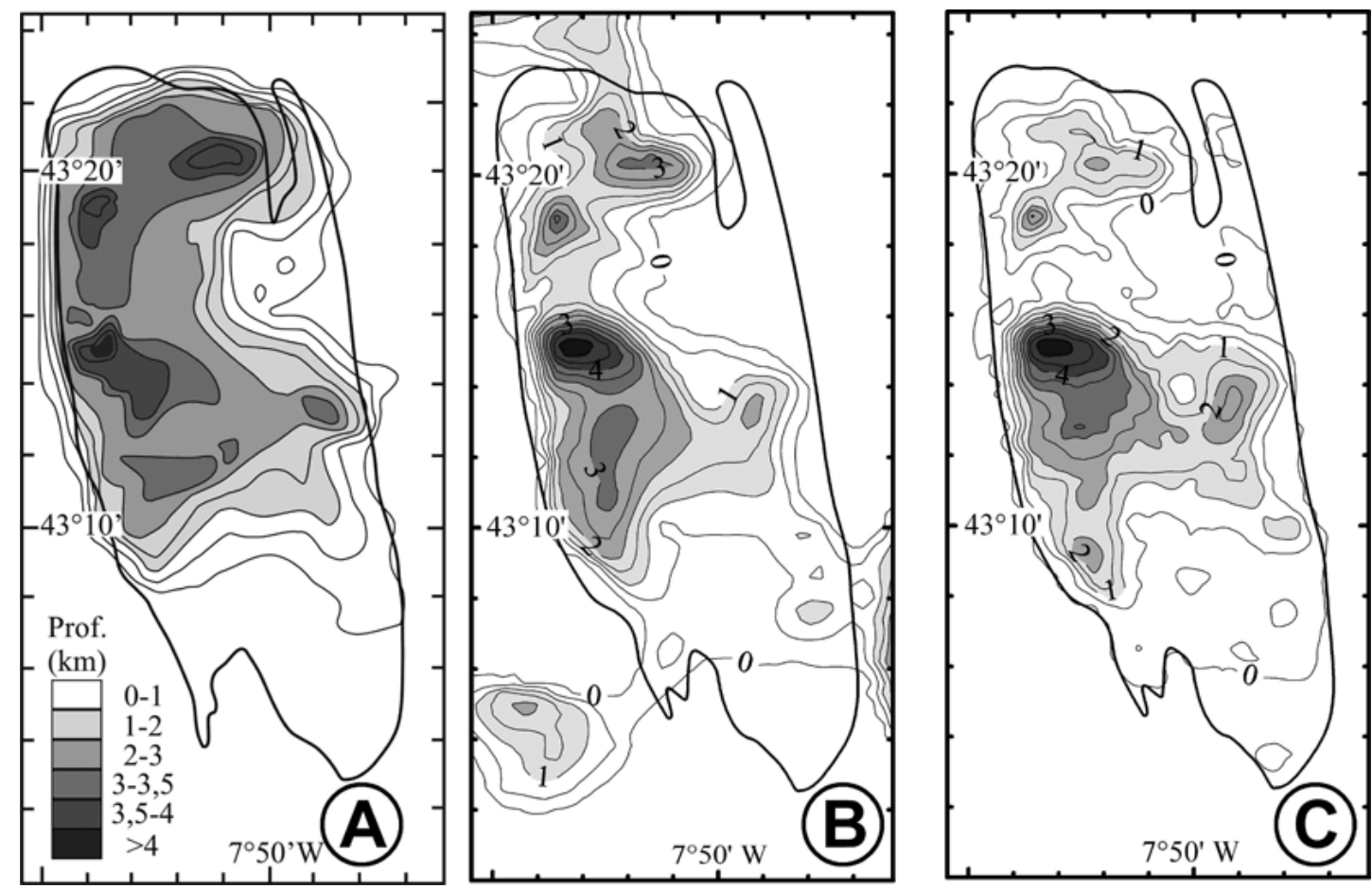

Figura 6 - Geometria interna do granito de Guitiriz obtida através de métodos de inversão gravimétrica 3-D. (A) Aranguren et al. (1995); (B) Embasamento homogêneo; e (C) Embasamento heterogêneo.

Ihas principais de borda são reativações eocretácicas de zonas de cisalhamento brasilianas (Françolin et al., 1994).

Os dados gravimétricos foram levantados pelo Laboratório de Geofísica de Prospecção e Sensoriamento Remoto da Universidade Federal do Ceará e integrados a levantamentos prévios (Castro et al., 2006). A componente regional do campo gravitacio- nal foi removida através do ajuste polinomial robusto, visto que as anomalias residuais refletem mais claramente a distribuição de densidade das fontes rasas da crosta superior. 0 mapa gravimétrico residual (Fig. 7b) mostra a excelente correlação entre os contatos superficiais da bacia e o mínimo gravimétrico que caracteriza a resposta geofísica desta fonte. Excepcionalmente, 


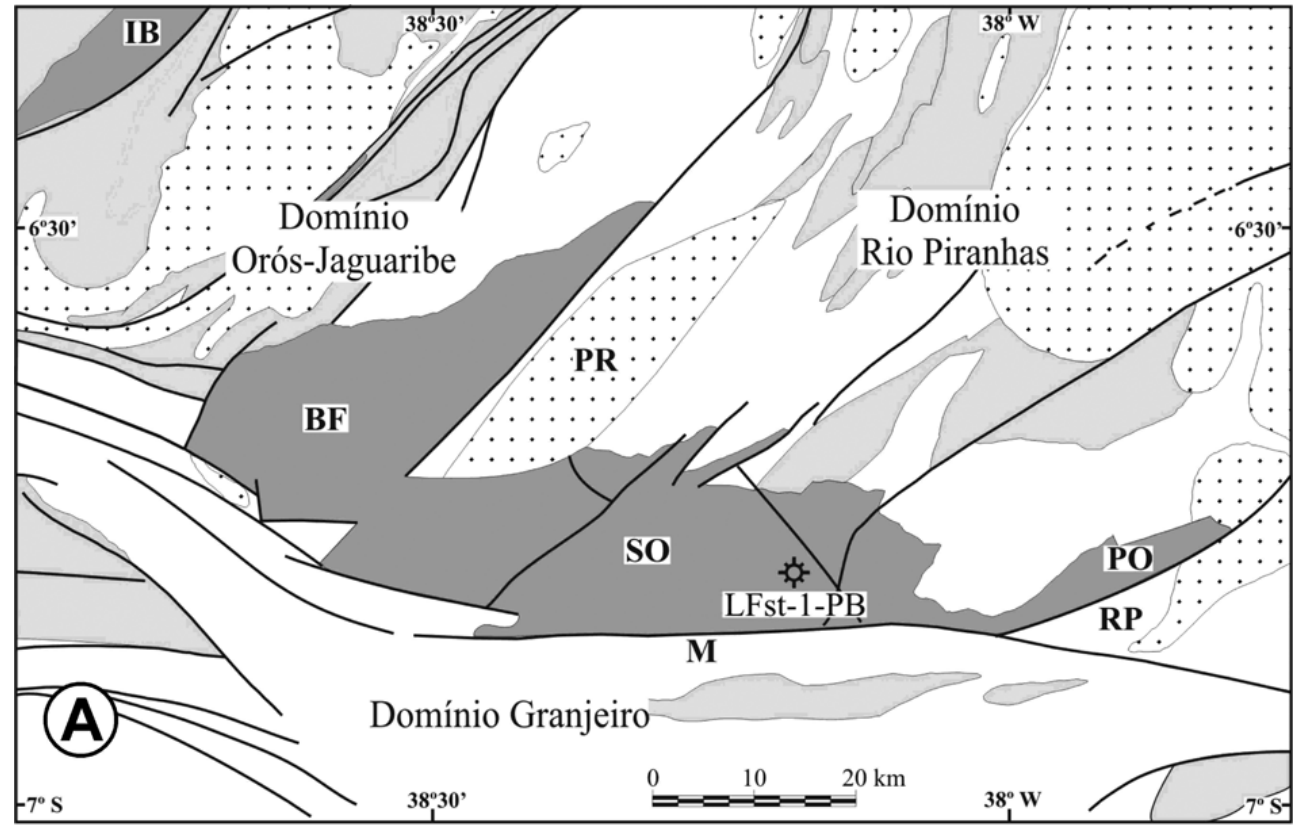

$\square_{1} \because: 2 \quad \square 3 \square 4 / 56$

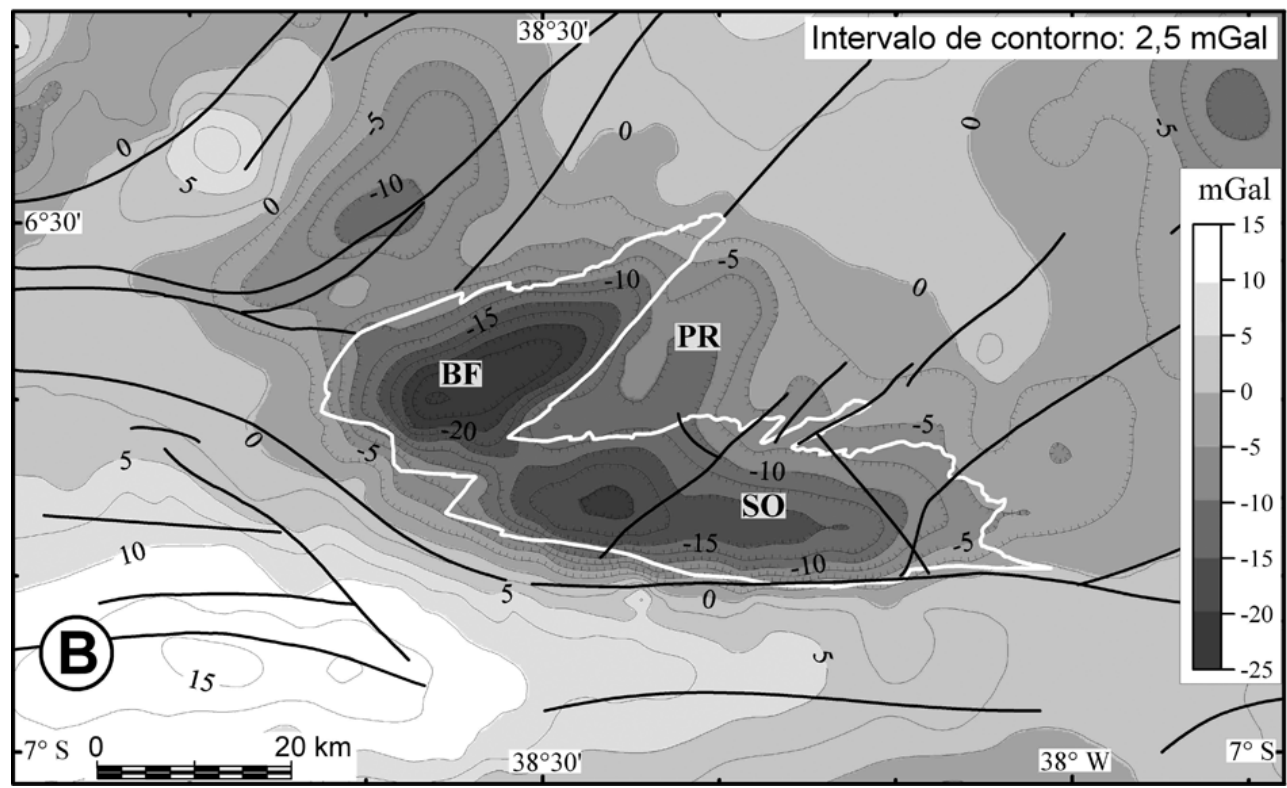

Figura 7 - Geologia da bacia Rio do Peixe (A), adaptada de Cavalcante (1999), e mapa de anomalias gravimétricas residuais (B). 1 Bacias rifte: Icó (IB) e Rio do Peixe (sub-bacias: Brejo das Freiras - BF, Souza - SO e Pombal - PO), 2: Granitos Brasilianos (PR: granito Paraná), 3: Sequêencias Neoproterozóicas, 4: Embasamento Paleoproterozóico, 5: Principais falhamentos, 6: Poço exploratório LFst-1-PB.

na borda NW da sub-bacia de Sousa (PR na Fig. 7) a anomalia negativa estende-se em direção norte, em resposta a presença do granito Paraná, que aflora nesta região (Sénant \& Popoff, 1991). Seu efeito gravimétrico negativo interfere nas anomalias negati- vas da bacia, violando localmente a premissa de embasamento homogêneo assumida pelos vários métodos de inversão citados neste trabalho.

Novamente, as técnicas de inversão para os casos do emba- 
samento homogêneo e heterogêneo foram testadas para a bacia Rio do Peixe. A escolha dos coeficientes da função quadrática que define a variação do contraste de densidade com a profundidade (Eq. 3) foi conduzida com base em medidas de densidade de amostras dos litotipos aflorantes na região e em dados de perfilagem geofísica realizada na bacia Potiguar, cuja história deposicional na sua fase rifte é bastante similar a da bacia Rio do Peixe (Castro et al., 2006). Os valores dos coeficientes ajustados pelo método dos mínimos quadrados foram: $a_{0}=-0,297$; $a_{1}=7,097 \times 10^{-5}$; e $a_{2}=-8,836 \times 10^{-11}$, dados em $\mathrm{g} / \mathrm{cm}^{3}$. Além disso, a presença do poço exploratório LFst-01-PB contribuiu para a parametrização final da densidade e uma análise estatística da precisão dos procedimentos inversos.

0 arcabouço geométrico da bacia obtido com a premissa do embasamento homogêneo mostra-se concordante com os seus contatos superficiais, revelando os semi-grabens, as falhas de borda e os principais depocentros (Fig. 8a). Contudo, o granito Paraná é incorporado indiscriminadamente ao modelo gravimétrico da bacia, fato já descrito por Castro \& Castelo Branco (1999) em uma modelagem preliminar realizada nas bacias do Vale do Cariri. 0 controle da geologia de superfície permite distinguir razoavelmente bem sua influência na modelagem gravimétrica da bacia. Contudo, a contribuição das porções não aflorantes ao modelo final não pode ser avaliada com precisão, contando-se apenas com os dados geológicos e geofísicos disponíveis.

Assumindo um embasamento heterogêneo com densidade variável, a geometria interna da bacia apresenta-se mais adequada à realidade geológica local (Fig. 8b). 0 efeito do granito foi satisfatoriamente isolado, inclusive 0 depocentro imediatamente a sul tem suas dimensões horizontais e vertical reduzidas. Tal fato sugere a influência gravimétrica das partes do granito que se encontram por baixo da bacia.

0 mapa gravimétrico sem 0 efeito da bacia, também obtido pelo procedimento de inversão, mostra as prováveis dimensões sub-superficiais do granito, indicadas por um mínimo gravimétrico de cerca de -10 mGal (PR na Fig. 9). Com exceção da borda norte, os contatos do granito parecem ser controlados estruturalmente pelas zonas de cisalhamentos brasilianas NE-SW e E-W, que afloram na região. Adicionalmente, percebe-se que a bacia Rio do Peixe está situada em uma região que predominam anomalias gravimétricas negativas devido à concentração de seqüências supracrustais e intrusões graníticas. Todo este efeito gravimétrico foi incorporado ao modelo geofísico da bacia quando da aplicação da técnica de inversão para o embasamento homogêneo (Fig. 8a).

\section{CONCLUSÕES}

0 presente trabalho aborda a modelagem gravimétrica 3-D de corpos graníticos e bacias sedimentares, inseridos em um contexto geológico, cujo embasamento estrutural apresenta variações de densidade. Ou seja, a presença de fontes interferentes viola parcial ou totalmente a premissa assumida em grande parte das técnicas de modelagem consagradas de que o problema geofísico a ser resolvido se restrinja a reconstituir uma interface que separa dois meios homogêneos. Neste sentido, foi adaptada e implementada uma metodologia de modelagem gravimétrica 3-D, a qual prevê variações de densidade no embasamento.

A partir de um procedimento iterativo, o efeito gravitacional da fonte alvo é separado da contribuição gravimétrica do embasamento e, então, invertido para gerar um modelo geofísico mais próximo a sua geometria interna. Testes com dados sintéticos, que simulam a assinatura gravimétrica de uma bacia sedimentar inserida em uma região intrudida por rochas ígneas, atestam um aumento considerável na resolução do modelo final, justamente nas áreas onde se encontram fontes interferentes à estrutura analisada.

A referida metodologia foi aplicada em duas situações geológicas com embasamentos heterogêneos. Para o Granito de Guitiriz no oeste da Espanha, o modelo final que considera fontes interferentes, neste caso corpos granitos associados e outras fontes locais com anomalias positivas, apresenta um melhor ajuste entre os contatos superficiais do granito e os limites definidos pela modelagem. Os condutos magmáticos estão aparentemente mais bem definidos, principalmente nas porções leste e sudeste do granito. E para a bacia Rio do Peixe no oeste da Paraíba, a introdução de um embasamento heterogêneo ao procedimento de inversão permitiu melhorar de sobremaneira a definição da arquitetura interna da bacia, principalmente na porção norte da subbacia Sousa, onde um corpo granítico (granito Paraná) representa um importante alto estrutural que promoveu a ancoragem da bacia. No modelo final, estruturas internas até então não mapeadas, como grabens e horsts secundários, podem agora ser individualizadas.

Outro importante produto desta técnica de inversão é o mapa de anomalias gravimétricas sem 0 efeito da fonte modelada. Este produto pode revelar feições geológicas que estejam sendo mascaradas pelo efeito gravimétrico da fonte em apreço. É o caso do granito Paraná, cuja anomalia gravimétrica só pôde ser observada após a retirada do mínimo gravimétrico devido à bacia Rio do Peixe. 

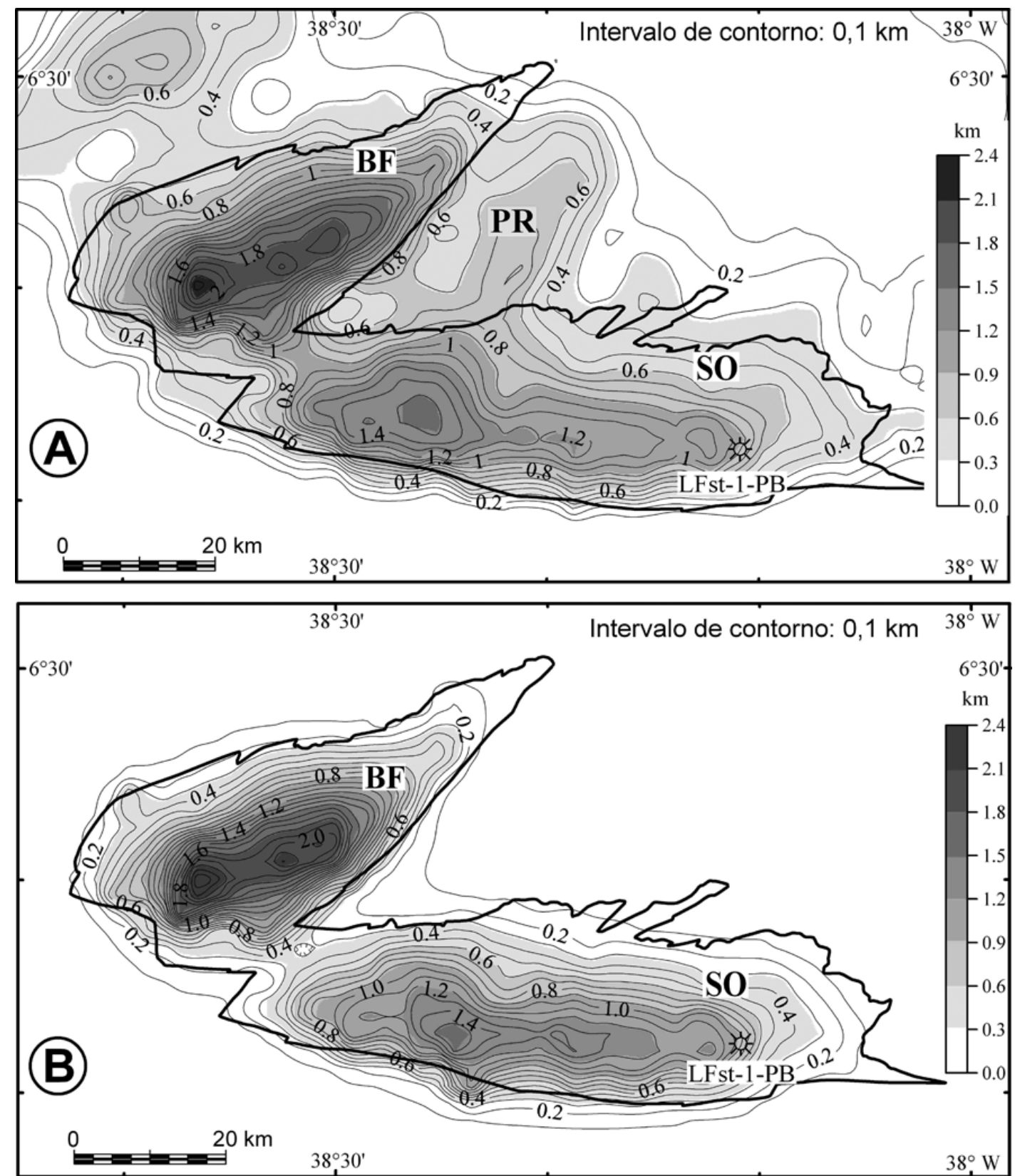

Figura 8 - Modelagem gravimétrica 3-D da bacia Rio do Peixe obtida segundo as premissas de embasamento homogêneo (A) e heterogêneo (B)

\section{AGRADECIMENTOS}

0 autor agradece às seguintes instituições pela cessão de dados gravimétricos e empréstimo de equipamentos geofísicos que permitiram a modelagem gravimétrica da bacia Rio do Peixe: Observatório Nacional, Instituto Brasileiro de Geografia e Estatística e Universidade Federal do Rio Grande do Norte. O levantamento gravimétrico teve apoio financeiro parcial da Universidade Federal do Ceará

\section{REFERÊNCIAS}

AL-CHALABI M. 1972. Interpretation of gravity anomalies by non-linear optimization. Geophysical Prospecting, 20: 1-16.

ARANGUREN A, TUBIA JM, BOUCHEZ JL \& VIGNERESSE JL. 1995. The Guitiriz granite, Variscan belt of northern Spain: extension-controlled emplacement of magma during tectonic escape. Earth and Planetary Science Letters, 139: 165-176.

BARBOSA VCF \& SILVA JBC. 1993. Reconstituição Gravimétrica Com- 


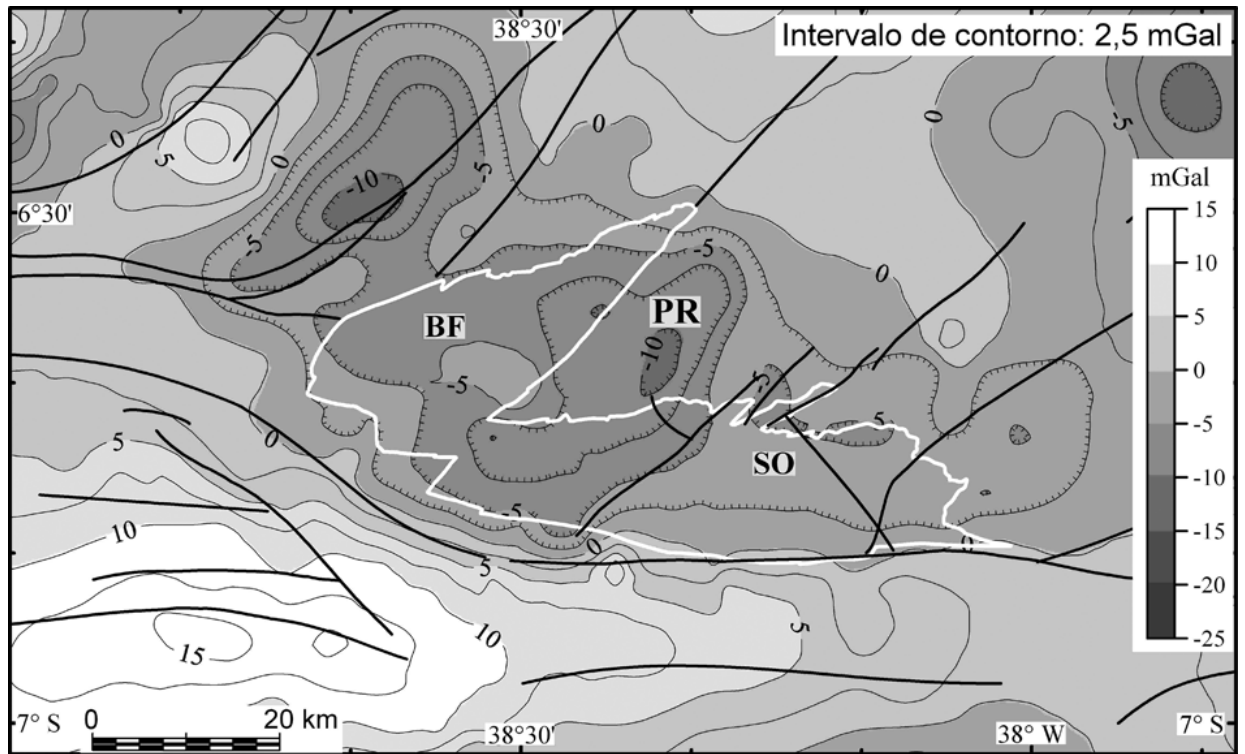

Figura 9 - Mapa de anomalias gravimétricas sem o efeito da bacia Rio do Peixe. Subbacias: BF: Brejo das Freiras e SO: Souza; PR: granito Paraná.

pacta. Anais do III Congresso Internacional da SBGf, Resumos Expandidos, 2: 765-767, Rio de Janeiro - RJ.

BARBOSA VCF, SILVA JBC \& MEDEIROS WE. 1999. Stable inversion of gravity anomalies of sedimentary basins with nonsmooth basement reliefs and arbitrary density contrast variations. Geophysics, 64(3): 754764

BELTRÃO JF, SILVA JBC \& COSTA JC. 1991. Robust polynomial fitting method for regional gravity estimation. Geophysics, 56: 80-89.

BLAKELY RJ. 1995. Potential theory in gravity and magnetic applications. Cambridge University Press, London, 441 pp.

BLAKELY RJ, JACHENS RC, CALZIA JP \& LANGENHEIM VE. 1999. Cenozoic basins of the Death Valley extended terrane as reflected in regional-scale gravity anomalies. Geological Society of America, Special Paper 333: 16 pp.

BOTT MHP. 1960. The use of rapid digital computing methods for direct gravity interpretation of sedimentary basins. Geophysical Journal of the Royal Astronomical Society, 3: 63-67.

BRAILE LW, KELLER GR \& PEEPLES WJ. 1974. Inversion of gravity data for two-dimensional density distributions. Journal of Geophysical Research, 79: 2017-2021.

CAMACHO AG, MONTESINOS FG \& VIEIRA R. 2002. A 3-D gravity inversion tool based on exploration of model possibilities. Computers \& Geosciences, 28: 191-204.

CASTRO DL \& CASTELO BRANCO RMG. 1999. Caracterização da arquitetura interna das bacias do Vale do Cariri (NE do Brasil) com base em modelagem gravimétrica 3-D. Revista Brasileira de Geofísica, 17 (2,3): 129-144.

CASTRO DL, CASTELO BRANCO RMG, MARTINS G \& CASTRO NA 2002. Radiometric, magnetic, and gravity study of the Quixadá Batholith, Central Ceará Domain (NE-Brazil): Evidence for an extension controlled emplacement related to the Pan-African/Brasiliano collage. Journal of South American Earth Sciences, 15 (5): 543-551.

CASTRO DL, OLIVEIRA DC \& CASTELO BRANCO RMG. 2006. On the Tectonics of the Neocomian Rio do Peixe rift basin, NE Brazil: Lessons from gravity, magnetics and radiometric data. Tectonophysics, artigo revisado pelos autores em fevereiro de 2006, $32 \mathrm{pp}$.

CAVALCANTE JC. 1999. Limites e evolução geodinâmica do sistema Jaguaribeano, Província Borborema, Nordeste do Brasil. Dissertação de Mestrado, UFRN, Natal, 183 pp.

CONDI FJ, ZELT CA, SAWYER DS \& HIRASAKI GJ. 1999. Gravity inversion for rifted margin deep structure using extension and isostatic constraints. Geophysical Journal International, 138: 435-446.

CORDELL L \& HENDERSON RG. 1968. Iterative three dimensional solution of gravity anomaly used a digital computer. Geophysics, 33: 596601.

COSTA AFU, FERNANDES LAD, SHUKOWSKY W, NARDI LVS \& BITENCOURT MF. 1995. Teste dos modelos tectônicos de posicionamento do complexo granítico de Caçapava do Sul através de estudos de modelagem gravimétrica 3-D. Revista Brasileira de Geofísica, 13 (2): 91-101.

COWIE PA \& KARNER GD. 1990. Gravity effect of sediment compaction: examples from the North Sea and the Rhine Graben. Earth and Planetary Science Letters, 99: 141-153. 
FRANÇOLIN JBL, COBBOLD PR \& SZATMARI P. 1994. Faulting in the Early Cretaceous Rio do Peixe basin (NE Brazil) and its significance for the opening of the Atlantic. Journal of Structural Geology, 16 (5): 647661.

JACHENS RC \& MORING BC. 1990. Maps of thickness of Cenozoic deposits and the isostatic residual gravity over basement for Nevada. U.S. Geological Survey Open-File Report 90-404, scale 1:1,000,000.

LAST BJ \& KUBIK K. 1983. Compact gravity inversion. Geophysics, 48 (6): 713-721.

LI Y \& OLDENBURG DW. 1998. 3-D inversion of gravity data, Geophysics, 63: 109-119.

MATOS RMD. 1992. The northeast Brazilian rift system. Tectonics, 11 (4): 766-791.

MENKE W. 1984. Geophysical data analysis: discrete inverse theory: Academic Press, Orlando, 260 pp.

NAGENDRA R, PRASAD PVS \& BHIMASANKARAM VLS. 1994. Fortran program based on granser's algorithm for inverting a gravity field resulting from a density interface. Computers \& Geosciences, 22 (3): 219225 .

PARKER RL. 1973. The rapid calculation of potential anomalies. Geophysical Journal of the Royal Astronomical Society, 31 (4): 449-445.
RAO DB. 1986. Modelling of sedimentary basins from gravity anomalies with variable density contrast. Geophysical Journal of the Royal Astronomic Society, 84 (1): 207-212.

RAO DB \& BABU NR. 1991. A Fortran-77 computer program for threedimensional analysis of gravity anomalies with variable density contrast. Computers \& Geosciences, 17 (5): 655-667.

RAO DB, PRAKASH MJ \& BABU NR. 1990. 3D and 2-1/2D modeling of gravity anomalies with variable density contrast. Geophy. Prosp., 38 (4): 411-422.

SÉNANT J \& POPOFF M. 1991. Early Cretaceous extension in northeast Brazil related to the South Atlantic opening. Tectonophysics, 198: 35-46.

SILVA JBC, MEDEIROS WE \& BARBOSA VCF. 2001. Potential-field inversion: Choosing the appropriate technique to solve a geologic problem. Geophysics, 66 (2): 511-520.

TALWANI M \& EWING M. 1960. Rapid computation of gravitational attraction of three-dimensional bodies of arbitrary shape. Geophysics 24 : 203-225.

VIGNERESSE JL. 1995. Crustal regime of deformation and ascent of granitic magma. Tectonophysics, 249: 187-202.

\section{NOTA SOBRE O AUTOR}

David Lopes de Castro é Geólogo (UFRN, 1986), Mestre em Geofísica (UFPA, 1990) e Doutor em Geofísica (Univ. Kiel - Alemanha, 1995). Desde 2002, é Professor Adjunto do Departamento de Geologia da UFC, diretamente vinculado ao Laboratório de Geofísica de Prospecção e Sensoriamento Remoto (LGPSR) e associado ao Curso de Pós-graduação em Geologia da UFC. Seu principal interesse é Geofísica aplicada a Geofísica regional, bacias sedimentares, hidrogeologia e meio ambiente com o emprego de métodos potenciais, eletromagnéticos e elétricos. É membro da Sociedade Brasileira de Geofísica e Sociedade Brasileira de Geologia. 